\title{
Analisis Kebijakan Penetapan Harga Jual Rumah pada Perumahan PT. Nasaliansyah Developer Jambi
}

\author{
Laila Farhat ${ }^{1 *}$, Marnas ${ }^{2}$ \\ ${ }^{1,2}$ Sekolah Tinggi Ilmu Ekonomi Jambi \\ *Correspondence email: Lailafarhat75@yahoo.com
}

\begin{abstract}
This research was conducted to analyze the pricing policy set by the housing developer PT. Nasaliansyah Jambi, which aims to determine the selling price of sales proceeds. This research is a qualitative descriptive study that describes the determination of the selling price of the house by the developer of PT. Nasaliansyah Jambi, with survey methods and field research. The results of the study prove that by increasing the number of orders and the amount of income received by the housing developer PT. Nasaliansyah Jambi in 2015 amounted to 90 units until 2018 to a total of 420 housing units sold. Price affects the choice of type of house purchased by consumers. The selling price of a house is influenced by the price of the materials that will be used to build a house. Likewise, promotional costs affect sales volume, the greater the promotion costs, the higher the sales volume of houses in PT. Nasaliansyah Jambi.
\end{abstract}

Keywords: Selling Price, Pricing, Consumer, Developers.

\section{Pendahuluan}

Undang-Undang No. 1 Tahun 2011 tentang Perumahan dan Permukiman bahwa dalam pembangunan nasional yang pada hakikatnya adalah pembangunan manusia Indonesia seutuhnya dan pembanguan seluruh masyarakat Indonesia, perumahan dan pemukiman yang layak, sehat, aman, serasi, dan teratur merupakan salah satu kebutuhan dasar manusia dan merupakan faktor penting dalam peningkatan harkat dan martabat, mutu kehidupan serta kesejahteraan rakyat dalam masyarakat adil dan makmur berdasarkan Pancasila dan UUD 1945. TAP MPR No. 11/MPR/2011 diamanatkan juga bahwa pembangunan perumahan dan pemukiman merupakan upaya untuk memenuhi kebutuhan dasar manusia sekaligus untuk meningkatkan mutu lingkungan, kehidupan, memberi arah pada pertumbuhan wilayah, memperluas lapangan kerja serta kegiatan ekonomi dalam rangka peningkatan dan pemerataan kesejahteraan rakyat, jadi sangat jelas bahwa rumah menjadi kebutuhan dasar manusia yang juga berpengaruh terhadap harkat dan martabat bangsa.

Berikut ini yang merupakan faktor-faktor yang mempengaruhi pertumbuhan pembangunan perumahan di Indonesia diantaranya adalah (1) peningkatan jumlah penduduk, peningkatan jumlah penduduk yang terjadi di Indonesia disebabkan oleh tingginya angka kelahiran; (2) kelangkaan tanah, kelangkaan tanah yang terjadi di Kota Jambi dikarenakan semakin banyaknya orang yang memilih tempat tinggal di Kota Jambi yang dianggap sebagai tempat yang paling strategis. Hal ini yang membuat nilai jual objek pajak (NJOP) menjadi tinggi; dan (3) faktor kelembagaan, faktor kelembagaan menjadi faktor yang sangat mendukung terlaksananya pelaksanaan pembangunan seperti lembaga pembiayaan. Perusahaan selalu berusaha memasarkan produknya agar bisa diterima oleh konsumen dan melalui produk itulah perusahaan bisa bertahap hidup. Namun yang menjadi masalah bagaimana produk tersebut bisa diterima oleh konsumen. Hal ini yang harus bisa dipecahkan oleh manajemen perusahaan. Salah satu hal yang penting dipikirkan oleh manajemen adalah kebijakan harga jual produknya secara tepat. Karena harga yang tidak tepat akan berakibat fatal yakni tidak menarik bagi para konsumen (pembeli) untuk membeli produk tersebut.

Kebijakan harga jual produk juga merupakan bagian dari kegiatan pemasaran yaitu memberikan kepuasan kepada para konsumen (pembeli) agar perusahaan dapat mencapai tujuan yang diinginkan. Sebelum menetapkan harga, perusahaan harus memutuskan strategi produknya. Jika perusahaan sudah memilih pasar sasaran dan melakukan positioning secara hati-hati, maka bauran pemasarannya, termasuk harga akan mudah ditentukan. Harga adalah satu-satunya elemen bauran pemasaran yang menghasilkan penerimaan, semua elemen lain merupakan biaya. Harga juga merupakan salah satu bauran pemasaran yang paling fleksibel karena harga dapat diubah dengan cepat pada waktu yang sama. Penetapan harga dan persaingan harga adalah masalah utama yang dihadapi oleh bagian pemasaran. Arti pentingnya harga semakin disadari oleh perusahaan, sebab dengan penetapan harga yang tepat akan meningkatkan volume penjualan bagi perusahaan.

\section{Metode}

Penelitian ini dilakukan dengan menggunakan meotde deskriptif kualitatif untuk mengetahui kebijakan penetapan harga terhadap volume penjualan pada PT. Nasaliansyah Jambi. Dapat diketahui tentang pelaksanaan kebijakan penetapan harga pada perumahan PT. Nasaliansyah Jambi serta pengaruhnya terhadap hasil penjualan produk. Metode deskriptif kualitatif untuk mengetahui kebijakan penetapan harga terhadap volume penjualan (order) 
pada PT. Nasaliansyah Jambi. Dapat diketahui tentang pelaksanaan kebijakan penetapan harga pada perumahan PT. Nasaliansyah Jambi serta pengaruhnya terhadap hasil penjualan produk. Tahap analisis data merupakan tahap akhir dari metodologi statistik, sebelum melakukan penarikan kesimpulan yang merupakan titik akhir dari permasalahan, berupa keputusan atau rencana yang menjadi jawaban terbaik dari permasalahan tersebut.

\section{Hasil}

Perusahaan menetapkan kebijakan harga sesuai dengan Peraturan Menteri Negara Perumahan Rakyat No. 7 Tahun 2007 tentang : Pengadaan Perumahan dan Pemukiman dengan dukungan fasilitas subsidi perumahan. Berdasarkan kebijakan tersebut perumahan PT. Nasaliansyah Jambi menetapkan harga sebagai berikut.

1) Type 36 dengan harga $\mathrm{Rp} 226.000 .000$ dengan uang muka sebesar Rp 46.000.000 KPR sebesar Rp 180.000.000

2) Type 48 dengan harga Rp 285.000.000 dengan uang muka sebesar Rp 55.000.000 dan KPR sebesar Rp 230.000 .000

3) Type 68 dengan harga Rp 367.000.000 dengan uang muka sebesar Rp 67.000.000 KPR sebesar Rp 300.000.000

Tabel 1

Biaya Promosi Penjualan Rumah Pada Perumahan PT. Nasaliansyah Jambi Tahun 2014-2018 (Dalam Jutaan Rupiah)

\begin{tabular}{|c|c|c|c|c|c|}
\hline Type Rumah & 2014 & 2015 & 2016 & 2017 & 2018 \\
\hline Type 36 & 15 & 10 & 20 & 25 & 30 \\
\hline Type 48 & 5 & 4 & 10 & 15 & 20 \\
\hline Type 68 & 4 & 3 & 7 & 8 & 10 \\
\hline Total & 19 & 17 & 37 & 48 & 60 \\
\hline
\end{tabular}

Sumber : Perumahan PT. Nasaliansyah Jambi Tahun 2019

Berdasarkan tabel 1 biaya promosi tahun 2014 dengan type 36 biaya promosi yang dikeluarkan sebesar Rp 15.000.000, type 48 biaya promosi $\mathrm{Rp} 3.000 .000$, dan type 68 biaya promosi yang dikeluarkan sebesar $\mathrm{Rp} 4.000 .000$ dengan total biaya promosi pada 2014 sebesar Rp 19.000.000. Pada tahun 2015 biaya promosi dengan type rumah 36 sebesar Rp 10.000.000, type 48 sebesar Rp 4.000.000 dan type 68 sebesar Rp 3.000.000 dengan total pada tahun 2015 sebesar Rp 17.000.000 terjadi penurunan biaya promosi sebesar 3,2\% dikarenakan pada tahun 2016 merupakan tahun awal kegiatan operasional perusahaan. Pada tahun 2016 biaya promosi sebesar biaya promosi dengan type 36 sebesar Rp 20.000.000, type 48 sebesar Rp 10.000.000 dan type 68 sebesar Rp 7.000.000 terjadi peningkatan biaya promosi sebesar 6,2\%. Pada tahun 2017 biaya promosi dengan type 36 sebesar Rp 25.000.000, type 48 sebesar Rp 15.000.000 dan type 68 sebesar Rp 8.000.000 terjadi peningkatan biaya promosi sebesar 17,7\%. Pada tahun 2018 biaya promosi Rp 30.000.000, type 48 sebesar Rp 20.000.000 dan sebesar Rp 10.000.000 terjadi peningkatan biaya promosi sebesar $29 \%$.

Adapun bentuk-bentuk promosi yang dilakukan oleh PT. Nasaliansyah Jambi adalah sebagai berikut:

1. Media Cetak, perusahaan melakukan promosi melalui media cetak berupa koran dengan memanfaatkan jasa koran Tribun Jambi. Dengan penyebaran informasi mealui koran diharapkan lebih banyak lagi konsumen yang mengetahui informasi keberadaan perusahaan sehingga mampu menarik perhatian konsumen untuk membeli produk tersebut.

2. Brosur, perusahaan melakukan promosi melalui pemberian brosur di kantor pemerintahan, Bank dan melalui karyawan kantor dan menyediakan langsung di kantor pemasaran.

3. Media Elektronik, perusahaan melakukan promosi dengan memanfaatkan media Elektronik dalam hal ini menggunakan Televisi yaitu Jambi TV dan Radio untuk memasarkan produk perusahaan.

Tabel 2

Harga Penjualan Rumah Pada Perumahan PT. Nasaliansyah Jambi Tahun 2014-2018 (Dalam Jutaan Rupiah)

\begin{tabular}{llrrrrr}
\hline \multicolumn{1}{c}{ Type Rumah } & $\mathbf{2 0 1 4}$ & $\mathbf{2 0 1 5}$ & $\mathbf{2 0 1 6}$ & $\mathbf{2 0 1 7}$ & 205 & $\mathbf{2 0 1 8}$ \\
\hline Type 36 & 157 & 175 & 195 & 226 \\
Type 48 & 185 & 225 & 231 & 255 & 285 \\
Type 68 & 250 & 285 & 348 & 355 & 367 \\
\hline
\end{tabular}

Sumber : Perumahan PT. Nasaliansyah Jambi Tahun 2019

Tabel 2 pada tahun 2014 dengan type 36 dijual dengan harga Rp 157.000.000, type 48 dengan harga Rp 185.000.000, dan type 68 dengan harga Rp 250.000.000 Pada tahun 2015 dengan type rumah 36 dijual dengan harga Rp 175.000.000, type 48 dengan harga Rp 225.000.000 dan type 68 dengan harga Rp 285.000.000. Pada tahun 2016 dengan type 36 dijual denagn harga $\mathrm{Rp} 195.000 .000$, type 48 dengan harga $\mathrm{Rp} 231.000 .000$ dan type 68 sebesar $\mathrm{Rp}$ 348.000.000. Pada tahun 2017 dengan type 36 dijual dengan harga $\mathrm{Rp} 205.000 .000$, type 48 dengan harga Rp 
255.000.000 dan type 68 dengan harga Rp 355.000.000. Pada tahun 2018 type 36 dengan harga Rp 226.000.000, type 48 dengan harga Rp 285.000.000 dan type 68 dengan harga Rp 367.000.000. Dilihat dari Tabel 2 harga rumah pada PT. Nasaliansyah Jambi setiap tahun terjadi kenaikan harga rumah berdasarkan type rumah yang tersedia pada PT. Nasaliansyah Jambi. Kenaikan ini terjadi sehubungan dengan kenaikan material bangunan yang setiap tahunnya terjadi kenaikan.

Tabel 3

Jumlah Rumah yang terjual Pada Perumahan PT. Nasaliansyah Jambi Tahun 2014 - 2018

\begin{tabular}{|c|c|c|c|c|c|}
\hline Type Rumah & 2014 & 2015 & 2016 & 2017 & 2018 \\
\hline Type 36 & 60 & 100 & 150 & 180 & 230 \\
\hline Type 48 & 20 & 50 & 70 & 90 & 110 \\
\hline Type 68 & 10 & 20 & 40 & 60 & 80 \\
\hline
\end{tabular}

Sumber : Perumahan PT. Nasaliansyah Jambi Tahun 2019

Tabel 3 dapat diketahui bahwa jumlah rumah yang terjual pada PT. Nasaliansyah Jambipada tahun 2014 dengan type 36 sebanyak 60 unit, type 48 yang terjual sebanyak 20 unit dan type 68 yang terjual sebanyak 10 unit. Pada tahun 2015 dengan type 36 sebanyak 100 unit, type 48 yang terjual sebanyak 50 unit dan type 68 yang terjual sebanyak 20 unit. Pada tahun 2016 dengan type 36 sebanyak 150 unit, type 48 yang terjual sebanyak 70 unit dan type 68 yang terjual sebanyak 40 unit. Pada tahun 2017 dengan type 36 sebanyak 180 unit, type 48 yang terjual sebanyak 90 unit dan type 68 yang terjua sebanyak 60 unit. Pada tahun 2018 dengan type 36 sebanyak 230 unit, type 48 yang terjual sebanyak 110 unit dan type 68 yang terjual sebanyak 80 unit. Dilihat dari tabel 3 jumlah rumah yang terjual pada PT. Nasaliansyah Jambi setiap tahun terjadi kenaikan jumlah rumah yang terjual berdasarkan type rumah, yang tersedia dan type 36 lebih dominan menjadi pilihan konsumen. Dalam hal ini harga mempengaruhi pilihan konsumen dalam menentukan type yang akan dipilih.

\section{Analisis Kebijakan Penetapan Harga Penjualan pada Perumahan PT. Nasaliansyah Jambi}

Pada PT. Nasaliansyah Jambi dapat diketahui bahwa setiap tahun terjadi peningkatan biaya promosi, harga semakin mahal dan jumlah unit rumah yang terjual semakin meningkat. Biaya promosi yang semakin meningkat dapat diketahui pada tahun 2014 sebesar Rp 19.000.000 sampai pada tahun 2018 menjadi sebesar Rp 60.000.000. pada tahun 2015 biaya promosi lebih besar dari pada tahun 2016 dikarenakan pada tahun 2015 merupakan awal kegiatan operasional perusahaan sehingga pada tahun tersebut lebih banyak mempromosikan keberadaan perusahaan dibandingkan dengan mempromosikan produk perusahaan dan pada tahun selanjutnya mengalami peningkatan secara terus menerus. Harga rumah yang semakin meningkat dikarenakan semakin mahalnya biaya material bahan baku yang digunakan untuk memproduksi rumah yang merupakan produk dari perumahan PT. Nasaliansyah Jambi. Tentu saja hal itu akan mempengaruhi harga rumah yang ditetapkan oleh perusahaan. Perusahaan juga menggunakan bahan yang berkualitas untuk mempertahankan mutu dan kualitas rumah yang dibangun agar dapat memenuhi kebutuhan konsumen serta sebagai kiat untuk mempertahankan pelanggan. Jumlah rumah yang terjual yang semakin meningkatkan dapat dilihat dari tahun 2014 total penjualan sebanyak 90 unit dan pada tahun 2018 menjadi 420 unit. Dikarenakan banyaknya konsumen yang membutuhkan tempat tinggal sebagai akibat dari besarnya pertumbuhan penduduk. Dengan angka kelahiran yang semakin meningkat maka semakin meningkat pula kebutuhan akan rumah. Tabel 1 yaitu biaya promosi dan Tabel 3 yang merupakan tabel jumlah rumah yang terjual pada PT. Nasaliansyah Jambi dapat diketahui bahwa semakin besar biaya promosi maka volume penjualan semakin meningkat. Sehingga biaya promosi mempengaruhi volume penjualan pada PT. Nasaliansyah Jambi.

\section{Simpulan} berikut :

Berdasarkan pembahasan yang telah dikemukakan sebelumnya, diperoleh beberapa kesimpulan sebagai

1. Dari kebijakan penetapan harga yang ditetapkan oleh perumahan PT. Nasaliansyah Jambi yang bertujuan untuk menetapkan harga jual terhadap hasi penjualan terbukti dengan meningkatkan jumlah order dan jumlah pendapatan yang diterima oleh perumahan PT. Nasaliansyah Jambi tahun 201590 unit sampai 2018 menjadi 420 unit.

2. Harga mempengaruhi pilihan type rumah yang dibeli oleh konsumen

3. Harga jual sebuah rumah dipengaruhi oleh harga material bahan yang akan digunakan untuk membangun sebuah rumah.

4. Biaya promosi mempengaruhi volume penjualan, semakin besar biaya promosi maka semakin meningkat volume penjualan rumah pada perumahan PT. Nasaliansyah Jambi. 


\section{Daftar Pustaka}

Basu Swastha, 2010, Asas-asas Marketing, Edisi 2, penerbit Liberty, Yogyakarta.

Fandy Tjiptono, 2010, Strategi Pemasaran, Edisi 2, Penerbit Andi, Yogyakarta.

Freddy Rungkuty, 2015, Riset Pemasaran, Penerbit PT. Gramedia Pustaka Utama, Jakarta.

Gunawan Adi Saputro, dan Marwan Asri, 2006, Anggaran Perusahaan, Penerbit BPFE, Yogyakarta.

Husein Umar, 2018, Metodologi Penelitian Aplikasi dalam Pemasaran, Cetakan 2, PT. Gramedia Pustaka Utama, Jakarta.

Kotler, Phillip, 2012, Manajemen Pemasaran, edisi Millenium, jilid I, diterjemahkan oleh Hendra Teguh, Rommy A., Rusli dan Benyamin Molan, Penerbit Prenhallindo, Jakarta.

Kotler, Philip dan Amstrong, Gary, 2012, Dasar-Dasar Pemasaran, edisi bahasa Indonesia, Jilid I dan 2, diterjemahkan oleh Alexander Sindiro, Penerbit Prenhallindo, Jakarta. 